AperTO - Archivio Istituzionale Open Access dell'Università di Torino

\title{
Age as a long-term prognostic factor in bariatric surgery
}

\section{This is the author's manuscript}

Original Citation:

Availability:

This version is available http://hdl.handle.net/2318/120769

since

Published version:

DOI:10.1097/SLA.0b013e3182734113

Terms of use:

Open Access

Anyone can freely access the full text of works made available as "Open Access". Works made available under a Creative Commons license can be used according to the terms and conditions of said license. Use of all other works requires consent of the right holder (author or publisher) if not exempted from copyright protection by the applicable law. 


\section{(3) \\ UNIVERSITÀ DEGLI STUDI DI TORINO}

This is an author version of the contribution published on:

Questa è la versione dell'autore dell'opera:

[Annals of Surgery,256, 5,2012, DOI: 10.1097/SLA.0b013e3182734113]

ovvero [autore, volume, editore, anno, pagg.XXXX-XXXX]

The definitive version is available at:

La versione definitiva è disponibile alla URL:

[http://journals.lww.com/annalsofsurgery/pages/articleviewer.aspx?year=2012\&issu $e=11000 \&$ article $=00008 \&$ type $=$ abstract $]$ 


\title{
Age as a Long-Term Prognostic Factor in Bariatric Surgery
}

\author{
Scozzari, Gitana MD*; Passera, Roberto PharmD, PhDt; Benvenga, Rosa MD*; Toppino,
} Mauro MD*; Morino, Mario MD*

Author Information

*Digestive, Colorectal and Minimal Invasive Surgery, University of Torino, Turin, Italy

${ }^{\dagger}$ AOU San Giovanni Battista and University of Torino, Turin, Italy.

\begin{abstract}
Objective: To analyze the potential effects of preoperative age on postoperative weight loss in patients who underwent Roux-en-Y gastric bypass (RYGBP) with long-term follow-up data.

Background: The reasons for individual differences in surgically induced weight loss are not completely understood. To date, there are no available studies specifically aimed at analyzing the effects of age on weight loss in patients undergoing the same operation and with long-term followup data.

Methods: Retrospective analysis of prospectively collected data for all patients who underwent RYGBP between 2006 and 2010. To evaluate weight loss, we used preoperative and follow-up body mass index (BMI), analyzed by the mixed-effects linear model for repeated measures. To evaluate age effects, patients were classified in quartiles $(<=35$ years, 36-42 years, $43-51$ years, $>=52$ years).

Results: A total of 489 patients entered the study; preoperatively, the younger group showed a significantly higher BMI (mean BMI: 48.2 in patients aged $<=35$ years, 46.9 in $36-42$ years, 45.5 in 43-51 years, 45.7 in $>=52$ years, $P=0.014)$ and a higher percentage of super-obesity $(41.6 \%$ among patients aged $<=35$ years, $28.1 \%$ among $36-42$ years, $27.6 \%$ among $43-51$ years, $28.3 \%$ among $>=52$ years, $P=0.047$ ). In spite of this, younger patients experienced a significantly greater and prolonged BMI decrease during the entire follow-up period and the BMI trend over time resulted significantly modified according to age quartiles $(\mathrm{P}=0.036)$.

Conclusions: This study provides a new prognostic factor in bariatric surgery: patient age. Because advanced age represents a risk factor for complications and mortality, and given that bariatric surgery may not be as effective in older patients compared to younger subjects, we believe that surgical indications in patients older than 50 years should be carefully weighed up.
\end{abstract}

Currently, bariatric surgery has largely demonstrated to be the only long-term effective therapy for the morbidly obese population: it markedly lowers body weight, reverses or ameliorates comorbidities, improves quality of life, and ultimately results in a decrease in overall mortality.1 Roux-en-Y gastric bypass (RYGBP) is the most widely performed bariatric operation, 2 and many studies have shown the safety and efficacy of this operation.3

Nevertheless, it is a common observation in clinical practice that postoperative weight reduction shows great disparities from one individual to another,4,5 with a consistent minority of patients (5\%-20\%) failing to achieve successful long-term weight loss.4,6

To date, the reasons for individual differences in surgically induced weight loss are not completely understood. Different studies have compared weight loss between type of surgery 7 or even different techniques of the same operation, 8 whereas others have analyzed several preoperative predictors, with discordant results.5,9-11 With regard to preoperative age, the few available published data have suggested that younger subjects could achieve a more satisfactory body weight loss, but we are unaware of studies specifically aimed at analyzing age effects on weight loss in a large cohort of patients undergoing the same operation. Furthermore, the few available data are lacking in long-term follow-up, a critical aspect in the analysis of bariatric surgery results. 
Another main concern in bariatric surgery studies is that statistical evaluation of postoperative results is usually complicated by missing observations either because of dropouts or because of subjects who miss one or more visits.12,13 The mixed-effects linear model for repeated measures represents a convenient statistical method that can assess changes in weight over time both within and among patients, allowing for differing numbers of data points per patient and accounting for missing values, by incorporation of all available data into a single model spanning the entire followup period.14 These characteristics make this statistical model ideal in longitudinal bariatric surgery studies.

In the present study, we aimed to examine the role of preoperative age as a potential predictor of weight loss outcome in a group of patients who underwent RYGBP using mixed-effects linear modeling.

\section{METHODS}

Study Population

All patients undergoing bariatric procedures at the Minimal Invasive Surgery Center of the University of Torino are registered in a prospective Bariatric Surgery Register, in which all demographic, anthropometric, perioperative, and reintervention data, together with weight loss and comorbidity results registered during follow-up visits, are noted. We conducted a retrospective analysis of these prospectively collected data for all patients who underwent RYGBP at our institution between January 1, 2006, and December 31, 2010. This is a consecutive series, and no inclusion or exclusion criteria were used. All patients who entered the study had a minimum followup of 12 months. Follow-up data were analyzed at the reference date of December 31, 2011. All patients who underwent primary RYGBP met the US National Institutes of Health consensus statement guidelines for bariatric surgery.15 For each patient, the following data were collected: gender, preoperative age, weight and height, BMI (calculated as weight in kilograms divided by height in meters squared), the preoperative presence and treatment of obesity-related comorbidities, and technical details of the surgical procedure.

\section{Surgical Technique}

All the surgical procedures were performed by 2 experienced bariatric surgeons (M.T., M.M.). The RYGBP was performed using either the open or laparoscopic approach. All the pouches were created with a volume less than $30 \mathrm{~mL}$ and were completely divided from the gastric fundus. The Roux limb length was measured at $150 \mathrm{~cm}$ in all patients. The gastrojejunostomy was created using different techniques: in 96 cases, it was constructed with hand-sewn 2-layer suture with absorbable suture over a 36-Fr endoluminal bougie, whereas in 393 cases, the gastrojejunostomy was mechanically performed using a circular stapler. The anastomosis was tested for patency and leakage using methylene blue tests, and a closed suction drain was placed near the gastrojejunal anastomosis in all cases. All patients received preoperative antibiotics and low molecular-weight heparin and wore thromboembolic stockings. Patients started fluids orally by the second day, after a gastrographin swallow. All patients received proton-pump inhibitors for 6 months postoperatively.

\section{Weight Loss Monitoring}

Patient follow-up was scheduled at 1 week, 30 days, 3 months, 6 months, and 12 months and annually thereafter. All patients were weighed at each visit. Preoperative weight data included height, weight, and BMI (calculated as weight in kilograms divided by height in meters squared); residual BMI was used to describe the postoperative weight loss results. 


\section{Statistical Analysis}

Prospective data were directly collected in our Bariatric Surgery Register, because no ethical approval was required for this study according to Italian law.

The primary outcome was the BMI trend over time after RYGBP and its potential modifications by 8 independent variables, measuring the BMI at several time points $(3,6,12,24,36,48$, and 60 months after RYGBP) and using its repeated measures as a dependent variable in different univariate and multivariate mixed-effects linear models. 14

At first, univariate analyses were performed for the following 8 independent variables: gender (male vs female); age at surgery by quartiles (>=52 vs $43-51$ vs $36-42$ vs $<=35$ years); preoperative BMI (classified in $<=50$ and $>50 \mathrm{~kg} / \mathrm{m}^{2}$, defining the latter as the cutoff for "super-obesity"); type II diabetes (any vs none, defining the presence of diabetes as the use of oral hypoglycemic agents and/or insulin); arterial hypertension (any vs none, defining the presence of hypertension as the use of any antihypertensive medications); type of surgery (secondary vs primary RYGBP, defining the former as revisional RYGBP in previous gastric banding or vertical banded gastroplasty); surgical approach (open surgery vs laparoscopy); and gastrojejunal anastomosis (circular stapled vs handsewn).

The multivariate model was then estimated by the restricted maximum likelihood method and using a first-order autoregressive covariance matrix: in other words, the BMI variance at each time point was considered comparable, whereas the correlations between subsequent BMI measures similar. The patients' characteristics were analyzed by the Fisher exact test for categorical variables and by the Mann-Whitney test for continuous ones. All reported P values were obtained by the 2-sided exact method, at the conventional 5\% significance level. Data were analyzed as of January 2012 with SPSS 20.0.0 and R 2.14.1.

\section{RESULTS}

\section{Patients' Baseline Characteristics}

Globally, 489 patients entered the study: 376 women (76.9\%) and 113 men (23.1\%). The patients' baseline characteristics are summarized in Table 1.

Mean age was $42.3 \pm 10.3$ years; age subgroups were classified in quartiles, as follows: 125 patients (25.6\%) were 35 years or younger, $128(26.2 \%)$ were aged 36 to 42 years, $123(25.2 \%)$ were aged 43 to 51 years, and $113(23.1 \%)$ were 52 years or older.

Mean preoperative weight and BMI were $126.9 \pm 23.3 \mathrm{~kg}$ and $46.6 \pm 7.5 \mathrm{~kg} / \mathrm{m}^{2}$, respectively. Preoperative BMI was $50 \mathrm{~kg} / \mathrm{m}^{2}$ or less in 335 patients $(68.5 \%)$ and greater than $50 \mathrm{~kg} / \mathrm{m}^{2}$ in 154 patients (31.5\%) (Fig. 1).

Classifying patients by age quartiles, preoperative BMI was significantly higher in the younger age group: mean BMI was $48.2 \pm 7.3 \mathrm{~kg} / \mathrm{m}^{2}$ in patients 35 years or younger, $46.9 \pm 7.1 \mathrm{~kg} / \mathrm{m}^{2}$ in 36 to 42 years, $45.5 \pm 7.7 \mathrm{~kg} / \mathrm{m}^{2}$ in 43 to 51 years, and $45.7 \pm 7.5 \mathrm{~kg} / \mathrm{m}^{2}$ in patients 52 years or older, respectively $(\mathrm{P}=0.014)$.

Furthermore, the percentage of super-obese patients, that is, patients with a preoperative BMI greater than $50 \mathrm{~kg} / \mathrm{m}^{2}$, was higher in the younger age group: super-obese patients were $41.6 \%$ among the patients 35 years or younger, $28.1 \%$ among those aged 36 to 42 years, $27.6 \%$ among those aged 43 to 51 years, and $28.3 \%$ among the patients 52 years or older, respectively $(\mathrm{P}=0.047$, Fig. 1).

Preoperative data on comorbidities were available for 451 patients; among these, 91 had type II diabetes $(20.2 \%)$ and 194 had hypertension (43.0\%). 
The RYGBP was a primary bariatric procedure in 403 patients $(82.4 \%)$ and a secondary, revisional operation in $86(17.6 \%)$. The surgical approach was open in 46 cases, whereas 443 patients underwent laparoscopic RYGBP; among the latter, 35 (7.9\%) underwent laparotomic conversion. In 96 cases (19.6\%), the gastrojejunal anastomosis was hand-sewn, whereas in 393 cases $(80.4 \%)$, the gastrojejunostomy was mechanically performed using a circular stapler.

\section{Weight Loss and Preoperative Factors}

Follow-up ranged between 12 and 72 months, with a median value of 36 months. Follow-up rates based on the sample that reached the time points of weight measurement at the reference date of December 31, 2011, were the following: $84.3 \%$ at 3 months, $82.4 \%$ at 6 months, $84.4 \%$ at 12 months, $80.5 \%$ at 24 months, $79.1 \%$ at 36 months, $57.5 \%$ at 48 months, and $47.9 \%$ at 60 months. Rates of patients lost to follow-up at different follow-up points showed no statistically significant differences between preoperative age groups (Table 2).

Postoperative BMI showed a statistically significant time trend: median BMI was $46.9 \mathrm{~kg} / \mathrm{m}^{2}$ before surgery, $38.9 \mathrm{~kg} / \mathrm{m}^{2}$ at 3-month follow-up, $34.6 \mathrm{~kg} / \mathrm{m}^{2}$ at 6 months, $31.2 \mathrm{~kg} / \mathrm{m}^{2}$ at 12 months, $30.5 \mathrm{~kg} / \mathrm{m}^{2}$ at 24 months, $31.4 \mathrm{~kg} / \mathrm{m}^{2}$ at 36 months, $31.7 \mathrm{~kg} / \mathrm{m}^{2}$ at 48 months, and $32.7 \mathrm{~kg} / \mathrm{m}^{2}$ at 60 months $(\mathrm{P}<0.001$, Fig. 2).

The lower BMI was reached at 24 months' follow-up. At this time point, mean BMI for all patients was $30.8 \pm 4.9 \mathrm{~kg} / \mathrm{m}^{2}$; classifying patients by age quartiles, mean BMIs were $30.5 \pm 4.6,29.9 \pm 5.2$, $30.9 \pm 4.7$, and $32.2 \pm 4.8 \mathrm{~kg} / \mathrm{m}^{2}$, for patients 35 years or younger, those aged 36 to 42 years, those aged 43 to 51 years, and patients 52 years or older, respectively.

At the final follow-up time point $(60 \mathrm{mo})$, mean BMI for all patients was $32.7 \pm 6.6 \mathrm{~kg} / \mathrm{m}^{2}$. Classifying patients by age quartiles, mean BMIs were $32.7 \pm 7.2,31.4 \pm 6.2,31.6 \pm 6.0$, and $36.9 \pm$ $6.7 \mathrm{~kg} / \mathrm{m}^{2}$, respectively, for each age subgroup.

In the univariate analyses, the BMI trend over time during the study period was not influenced by gender $(\mathrm{P}=0.848)$, type II diabetes $(\mathrm{P}=0.355)$, hypertension $(\mathrm{P}=0.083)$, and surgical approach $(\mathrm{P}$ $=0.459)$, whereas it was significantly modified by age quartiles $(\mathrm{P}=0.048)$, preoperative $\mathrm{BMI}(\mathrm{P}<$ $0.001)$, type of surgery, that is, primary or revisional RYGBP $(\mathrm{P}=0.008)$, and type of gastrojejunal anastomosis $(\mathrm{P}=0.002$, Table 3$)$.

In the multivariate analysis, the BMI trend over time was significantly modified only by age quartiles ( $\mathrm{P}=0.036$, Table 3, Fig. 3) and baseline BMI $(\mathrm{P}<0.001$, Table 3$)$.

\section{DISCUSSION}

After RYGBP, $5 \%$ to $20 \%$ of patients do not lose weight successfully, despite standardized surgical techniques and regular follow-up.6,16,17 Several preoperative predictors of poor weight loss have been studied, although most of them remain controversial, such as patient's gender 8,14,18,19 and the impact of obesity-related comorbidities such as diabetes mellitus.10,18-21

In the present study, to analyze the effects of demographic and operative variables on the BMI trend, we used the mixed-effects linear model for repeated measures.13,14 The main finding was that BMI decrease during study period was not influenced by gender, preoperative diabetes, hypertension, or technical surgical details, whereas BMI trend over time was significantly modified by baseline BMI $(\mathrm{P}<0.001)$ and baseline age less than 52 years $(\mathrm{P}=0.036)$. 
Although univariate analysis reported a difference in terms of BMI decrease based on type of surgery and type of anastomosis, both factors were not confirmed at the multivariate analysis. Thus, the results of the multivariate analysis of our data confirm the existing literature, showing that type of surgery and gastrojejunal construction do not significantly influence clinical results.22,23 In line with the available published data,5,6,8,14,17,24,26 super-obesity has shown in our analysis to be a strong risk factor for BMI trend over time. Even though heavier patients can lose greater absolute amounts of weight, they lose a smaller percentage of their excess weight than leaner patients, 27 and they tend to remain obese. 14

But the most important and not yet described result of the present study was that operative age was a statistically significant modifier of the BMI trend over time. Younger patients, although significantly heavier at baseline and with a higher super-obesity incidence $(42 \%$ in patients aged $<=$ 35 years compared to $28 \%$ in the $>=52$ years age group, Fig. 1), showed a lower mean BMI over time. The three youngest subgroups, i.e. patients aged from 19 to 51 years, showed a homogeneous BMI trend, whereas the older subgroup, i.e. patients aged $>=52$ years, showed a significantly lower BMI decrease, with a more consistent weight regain in the long-term follow-up (Fig. 3).

The role of preoperative age in bariatric surgery was rarely investigated. In 1977, the seminal study on the gastric bypass by Printen and Mason 28 found that patients aged older than 50 years lost $40 \%$ less weight 2 years after surgery than younger patients. Later, in 1989, another study supported the finding of lesser weight loss in older patients, reporting a significant positive correlation between postoperative BMI and age after gastric banding. 29

In the laparoscopic era, a few articles explored the relationship between preoperative age and weight loss but, although showing a trend in favor of younger patients, failed to reach any definitive conclusion because of the limited sample size or to the short follow-up.30,33 Recently, a systematic review conducted with the aim of identifying preoperative predictors of weight loss following bariatric surgery has been published 6; interestingly, patients' age was not included among the significant preoperative factors.

Compared with the literature data available, we believe that the present series shows consistent data on the role of older preoperative age as a negative prognostic factor, thanks to its large and homogeneous group of patients, long follow-up and high follow-up rates, and to a sophisticated statistical analysis that enables to overcome the main limitations of bariatric surgery series.

Moreover, patients lost to follow-up were equally represented among the different age groups, thus preventing selection bias.

Older age in bariatric surgery has been frequently studied as a predictor of postoperative complications, and surgical indications in the elderly people has always been a controversial topic, because the reported morbidity and mortality rates are significantly higher in older patients.9,34,36 In this respect, the less satisfactory weight loss of older patients should be taken into account when discussing indications to bariatric surgery.

Different physiopathological and behavioral hypothesis may explain the relationship between age and weight loss after bariatric surgery. Energy requirements normally decrease with age.32 It has been reported that, in normal body weight subjects, aging is associated with a lower lipolytic capacity,37 in particular after sympathetic stimulation,38 and this may explain the increased adipose tissue deposition of older subjects. Furthermore, blunted lipolytic activity has been described in obese, postmenopausal women subjected to a hypocaloric diet.39 This suggests that older obese women have a decreased capacity to supply energy through the mobilization of lipids from fat stores, and this could also condition a larger caloric intake after surgery. Interestingly, younger patients have been demonstrated to have a greater reduction of energy intake after RYGBP: in a study analyzing the modifications of energy intake and their impact on body weight after RYGBP in 50 obese patients,(24) subjects younger than 35 years reduced their energy intake significantly more than those older than 35 years and showed significantly greater weight loss. From the age of 40 years, total energy expenditure begins to decline, 40 and this age-dependent decrease seems to be mainly due to a reduction in physical activity. 41 The more sedentary lifestyle 
may be one reason for lower weight loss in patients older than 55 years:19,33,42 younger patients may have better exercise tolerance and more active lifestyles, and successful long-term weight maintenance is known to be associated with a physically active lifestyle.43 Furthermore, because obesity is not only a medical but also a social disease, 44 psychological and social aspects related to patient's age may account for postoperative weight loss and maintenance, because these are associated with internal motivation and social support.43 It has been reported that, with respect to attractiveness, younger obese people are denigrated to a greater degree than older obese subjects; 44 as a result, older individuals may be less inclined to maintain lower weights. Prospective studies are needed to further elucidate the role of patient age in influencing bariatric surgery results and to define physiopathological mechanisms of age-related weight loss and maintenance.

In conclusion, this study provides a new prognostic factor in bariatric surgery: the patient's age. This finding has, in our opinion, 2 important consequences in daily clinical bariatric practice: first, it allows practitioners to provide patients with a more realistic evaluation of the potential outcomes of the procedure; second, the less satisfactory weight loss should be taken into account when evaluating surgical indications in older patients.

\section{REFERENCES}

1. Sjöström L, Lindroos AK, Peltonen M, et al. Lifestyle, diabetes, and cardiovascular risk factors 10 years after bariatric surgery. N Engl J Med. 2004;351:2683-2693

2. Buchwald H, Avidor Y, Braunwald E, et al. Bariatric surgery: a systematic review and metaanalysis. JAMA. 2004;292:1724-1737

3. Sugerman HJ, Wolfe LG, Sica DA, et al. Diabetes and hypertension in severe obesity and effects of gastric bypass-induced weight loss. Ann Surg. 2003;237:751-756; discussion 757-758.

4. Maggard MA, Shugarman LR, Suttorp M, et al. Meta-analysis: surgical treatment of obesity. Ann Intern Med. 2005;142:547-559.

5. Lutfi R, Torquati A, Sekhar N, et al. Predictors of success after laparoscopic gastric bypass: a multivariate analysis of socioeconomic factors. Surg Endosc. 2006;20:864-867.

6. Livhits M, Mercado C, Yermilov I, et al. Preoperative predictors of weight loss following bariatric surgery: systematic review. Obes Surg. 2012;22:70-89.

7. Sugerman HJ, Londrey GL, Kellum JM, et al. Weight loss with vertical banded gastroplasty and Roux-Y gastric bypass for morbid obesity with selective versus random assignment. Am J Surg. 1989;157:93-102.

8. Stefanidis D, Kuwada TS, Gersin KS. The importance of the length of the limbs for gastric bypass patients - an evidence-based review. Obes Surg. 2011;21:119-124.

9. Nguyen NT, Rivers R, Wolfe BM. Factors associated with operative outcomes in laparoscopic gastric bypass. J Am Coll Surg. 2003;197:548-557.

10. Melton GB, Steele KE, Schweitzer MA, et al. Suboptimal weight loss after gastric bypass surgery: correlation of demographics, comorbidities, and insurance status with outcomes. $\mathbf{J}$

Gastrointest Surg. 2008;12:250-255.

11. Harvin G, DeLegge M, Garrow DA. The impact of race on weight loss after Roux-en-Y gastric bypass surgery. Obes Surg. 2008;18:39-42.

12. Gadbury GL, Coffey CS, Allison DB. Modern statistical methods for handling missing repeated measurements in obesity trial data: beyond LOCF. Obes Rev. 2003;4:175-184.

13. Mallinckrodt CH, Sanger TM, Dubé S, et al. Assessing and interpreting treatment effects in longitudinal clinical trials with missing data. Biol Psychiatry. 2003;53:754-760. 
14. Dallal RM, Quebbemann BB, Hunt LH, et al. Analysis of weight loss after bariatric surgery using mixed-effects linear modeling. Obes Surg. 2009;19:732-737.

15. Gastrointestinal surgery for severe obesity. Proceedings of a National Institute of Health Consensus Development Conference. March 25-27, 1991, Bethesda, MD. Am J Clin Nutr. 1992;55:487S-619S.

16. Salem L, Jensen CC, Flum DR. Are bariatric surgical outcomes worth their cost? A systematic review. J Am Coll Surg. 2005;200:270-278.

17. Christou NV, Look D, MacLean LD. Weight gain after short- and long-limb gastric bypass in patients followed for longer than 10 years. Ann Surg. 2006;244:734-740

18. Campos GM, Rabl C, Mulligan K, et al. Factors associated with weight loss after gastric bypass. Arch Surg. 2008;143:877-883; discussion 884.

19. Ma Y, Pagoto SL, Olendzki BC, et al. Predictors of weight status following laparoscopic gastric bypass. Obes Surg. 2006;16:1227-1231.

20. Coupaye M, Sabaté JM, Castel B, et al. Predictive factors of weight loss 1 year after laparoscopic gastric bypass in obese patients. Obes Surg. 2010;20:1671-1677.

21. Carbonell AM, Wolfe LG, Meador JG, et al. Does diabetes affect weight loss after gastric bypass? Surg Obes Relat Dis. 2008;4:441-444.

22. Gould JC, Garren M, Boll V, et al. The impact of circular stapler diameter on the incidence of gastrojejunostomy stenosis and weight loss following laparoscopic Roux-en-Y gastric bypass. Surg Endosc.2006;20:1017-1020.

23. Topart P, Becouarn G, Ritz P. One-year weight loss after primary or revisional Roux-en-Y gastric bypass for failed adjustable gastric banding. Surg Obes Relat Dis. 2009;5:459-462.

24. Bobbioni-Harsch E, Huber O, Morel P, et al. Factors influencing energy intake and body weight loss after gastric bypass. Eur J Clin Nutr. 2002;56:551-556.

25. Puzziferri N, Nakonezny PA, Livingston EH, et al. Variations of weight loss following gastric bypass and gastric band. Ann Surg. 2008;248:233-242.

26. Chen EY, McCloskey MS, Doyle P, et al. Body mass index as a predictor of 1-year outcome in gastric bypass surgery. Obes Surg. 2009;19:1240-1242.

27. Bloomston M, Zervos EE, Camps MA, et al. Outcome following bariatric surgery in super versus morbidly obese patients: does weight matter? Obes Surg. 1997;7:414-419

28. Printen KJ, Mason EE. Gastric bypass for morbid obesity in patients more than fifty years of age. Surg Gynecol Obstet. 1977;144:192-194.

29. Sjøberg EJ, Andersen E, Hoe1 R, et al. Gastric banding in the treatment of morbid obesity. Factors influencing immediate and long-term results. Acta Chir Scand. 1989;155:31-34

30. StPeter SD, Craft RO, Tiede JL, et al. Impact of advanced age on weight loss and health benefits after laparoscopic gastric bypass. Arch Surg. 2005;140:165-168.

31. Dunkle-Blatter SE St, Jean MR, Whitehead C, et al. Outcomes among elderly bariatric patients at a high-volume center. Surg Obes Relat Dis. 2007;3:163-170.

32. Rand CS, Macgregor AM. Age, obesity surgery, and weight loss. Obes Surg. 1991;1:47-49.

33. Frutos MD, Luján J, Hernández Q, et al. Results of laparoscopic gastric bypass in patients $>=55$ years old. Obes Surg. 2006;16:461-464.

34. Livingston EH, Huerta S, Arthur D, et al. Male gender is a predictor of morbidity and age a predictor of mortality for patients undergoing gastric bypass surgery. Ann Surg. 2002;236:576-582. 35. Flum DR, Salem L, Elrod JA, et al. Early mortality among Medicare beneficiaries undergoing bariatric surgical procedures. JAMA. 2005;294:1903-1908

36. Varela JE, Wilson SE, Nguyen NT, et al. Outcomes of bariatric surgery in the elderly. Am Surg. 2006;72:865-869.

37. Toth MJ, Tchernof A. Lipid metabolism in elderly. Eur J Clin Nutr. 2000;54(suppl 3):S121-125

38. Blaak EE. Adrenergically stimulated fat utilization and ageing. Ann Med. 2000;32:380-382.

39. Nicklas BJ, Rogus EM, Goldberg AP. Exercise blunts declines in lipolysis and fat oxidation after dietary-induced weight loss in obese older women. Am J Physiol. 1997;273:E149-E155. 
40. Manini TM. Energy expenditure and aging. Ageing Res Rev. 2010;9:1-11.

41. Lührmann PM, Bender R, Edelmann-Schäfer B, et al. Longitudinal changes in energy

expenditure in an elderly German population: a 12-year follow-up. Eur J Clin Nutr. 2009;63:986992.

42. van Hout GC, Verschure SK, van Heck GL. Psychosocial predictors of success following bariatric surgery. Obes Surg. 2005;15:552-560.

43. Elfhag K, Rössner S. Who succeeds in maintaining weight loss? A conceptual review of factors associated with weight loss maintenance and weight regain. Obes Rev. 2005;6:67-85.

44. Hebl MR, Ruggs EN, Singletary SL, et al. Perceptions of obesity across the lifespan. Obesity. 2008;16(suppl 2):S46-S52. 


\begin{tabular}{|c|c|c|}
\hline Variable & $\mathbf{N}$ & $\%$ \\
\hline $\mathrm{N}$ & 489 & \\
\hline \multicolumn{3}{|l|}{ Gender } \\
\hline Women & 376 & $76.9 \%$ \\
\hline Men & 113 & $23.1 \%$ \\
\hline Age (mean $\pm S D)$, years & $42.3 \pm 10.3$ & \\
\hline \multicolumn{3}{|l|}{ Age subgroups, yrs } \\
\hline$\leq 35$ & 125 & $25.6 \%$ \\
\hline $36-42$ & 128 & $26.2 \%$ \\
\hline $43-51$ & 123 & $25.2 \%$ \\
\hline$\geq 52$ & 113 & $23.1 \%$ \\
\hline $\mathrm{BMI}\left(\right.$ mean $\pm \mathrm{SD}$ ), $\mathrm{kg} / \mathrm{m}^{2}$ & $46.6 \pm 7.5$ & \\
\hline $\mathrm{BMI} \leq 50 \mathrm{~kg} / \mathrm{m}^{2}$ & 335 & $68.5 \%$ \\
\hline $\mathrm{BMI}>50 \mathrm{~kg} / \mathrm{m}^{2}$ & 154 & $31.5 \%$ \\
\hline \multicolumn{3}{|l|}{ Type II diabetes } \\
\hline No & 360 & $79.8 \%$ \\
\hline Yes & 91 & $20.2 \%$ \\
\hline Unknown & 38 & \\
\hline \multicolumn{3}{|l|}{ Hypertension } \\
\hline No & 257 & $57.0 \%$ \\
\hline Yes & 194 & $43.0 \%$ \\
\hline Unknown & 38 & \\
\hline \multicolumn{3}{|l|}{ Type of surgery } \\
\hline Primary RYGBP & 403 & $82.4 \%$ \\
\hline Revisional RYGBP & 86 & $17.6 \%$ \\
\hline \multicolumn{3}{|l|}{ Surgical approach } \\
\hline Laparoscopy & 408 & $83.4 \%$ \\
\hline Open surgery & 81 & $16.6 \%$ \\
\hline \multicolumn{3}{|l|}{ Gastrojejunal anastomosis } \\
\hline Hand-sewn & 96 & $19.6 \%$ \\
\hline Circular stapled & 393 & $80.4 \%$ \\
\hline
\end{tabular}

TABLE 1. Main Baseline Characteristics of Patients at Surgery

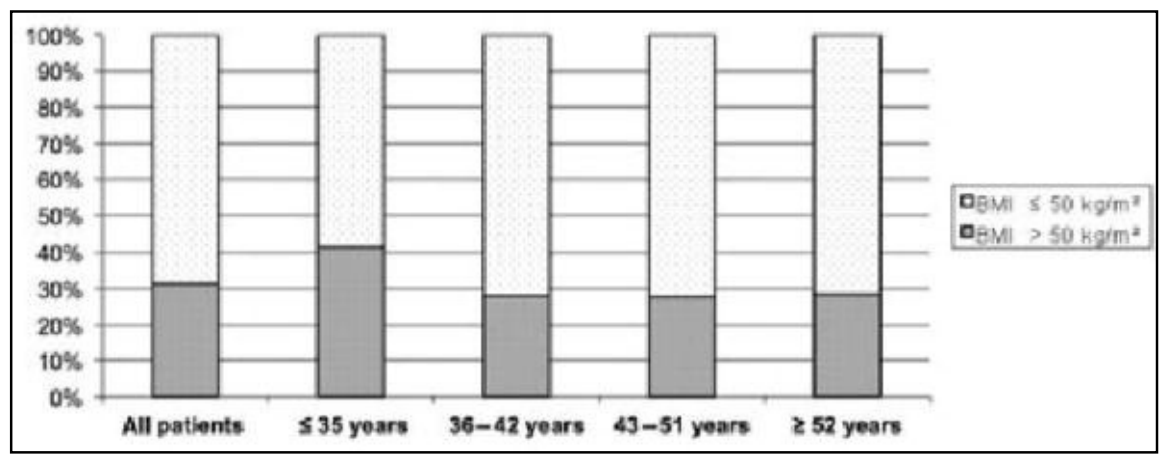

FIGURE 1 . Preoperative super-obesity incidence rates among age subgroups. 


\begin{tabular}{|lcccccc|}
\hline Time Point & All Patients & $\mathbf{3 5}$ Years & $\mathbf{3 6 - 4 2}$ Years & $\mathbf{4 3 - 5 1}$ Years & $\geq \mathbf{5 2}$ Years & $\boldsymbol{P}$ \\
\hline Preoperative & 489 & 125 & 128 & 123 & 113 & \\
3 months & $412 / 489$ & $107 / 125$ & $107 / 128$ & $106 / 123$ & $92 / 113$ & 1.000 \\
& $84.3 \%$ & $85.6 \%$ & $83.6 \%$ & $86.2 \%$ & $81.4 \%$ & \\
6 months & $403 / 489$ & $101 / 125$ & $108 / 128$ & $105 / 123$ & $89 / 113$ & 0.688 \\
& $82.4 \%$ & $80.8 \%$ & $84.4 \%$ & $85.4 \%$ & $78.8 \%$ & \\
12 months & $413 / 489$ & $108 / 125$ & $110 / 128$ & $102 / 123$ & $93 / 113$ & 1.000 \\
& $84.4 \%$ & $86.4 \%$ & $85.9 \%$ & $82.9 \%$ & $82.3 \%$ & \\
24 months & $317 / 394$ & $79 / 106$ & $84 / 106$ & $82 / 96$ & $72 / 86$ & 0.277 \\
& $80.5 \%$ & $74.5 \%$ & $79.2 \%$ & $85.4 \%$ & $83.7 \%$ & \\
36 months & $220 / 278$ & $55 / 78$ & $57 / 69$ & $54 / 66$ & $54 / 65$ & 0.237 \\
& $79.1 \%$ & $70.5 \%$ & $82.6 \%$ & $81.8 \%$ & $83.1 \%$ & \\
48 months & $115 / 200$ & $34 / 64$ & $26 / 52$ & $30 / 44$ & $25 / 40$ & 0.328 \\
& $57.5 \%$ & $53.1 \%$ & $50.0 \%$ & $68.2 \%$ & $62.5 \%$ & \\
60 months & $68 / 142$ & $16 / 41$ & $19 / 39$ & $21 / 35$ & $12 / 27$ & 0.435 \\
& $47.9 \%$ & $39.0 \%$ & $48.7 \%$ & $60.0 \%$ & $44.4 \%$ & \\
\hline Reported follow-up rates are based on the sample, which reached the time points of weight measurement at the \\
reference date of December 31,2011.
\end{tabular}

TABLE 2 . Number of Available Patients and Follow-Up Rates

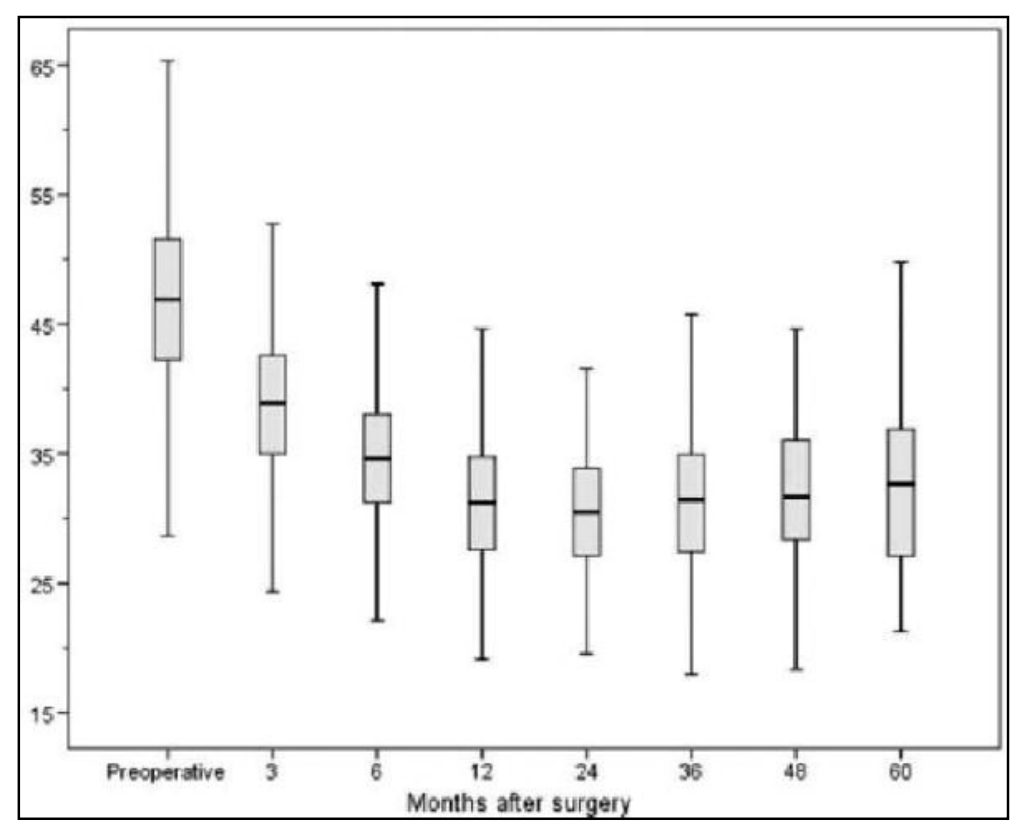

FIGURE 2 . Boxplots of BMI over time for the entire patient sample. 


\begin{tabular}{|lcc|}
\hline Variable & $\begin{array}{c}\text { Univariate } \\
\text { Analyses, } \boldsymbol{P}\end{array}$ & $\begin{array}{c}\text { Multivariate } \\
\text { Analysis, } \boldsymbol{P}\end{array}$ \\
\hline Gender & 0.848 & - \\
Age subgroup & $0.048^{*}$ & $0.036^{*}$ \\
Preoperative BMI & $<0.001^{*}$ & $<0.001^{*}$ \\
Type II diabetes & 0.355 & - \\
Hypertension & 0.083 & 0.283 \\
Type of surgery & $0.008^{*}$ & 0.161 \\
Surgical approach & 0.459 & - \\
Gastrojejunal anastomosis & $0.002^{*}$ & 0.307 \\
\hline \multicolumn{1}{|c}{${ }^{*}$ Statistically significant. } & & \\
\hline
\end{tabular}

TABLE 3 . Mixed Linear Models for BMI Repeated Measures From 3 to 60 Months After Surgery

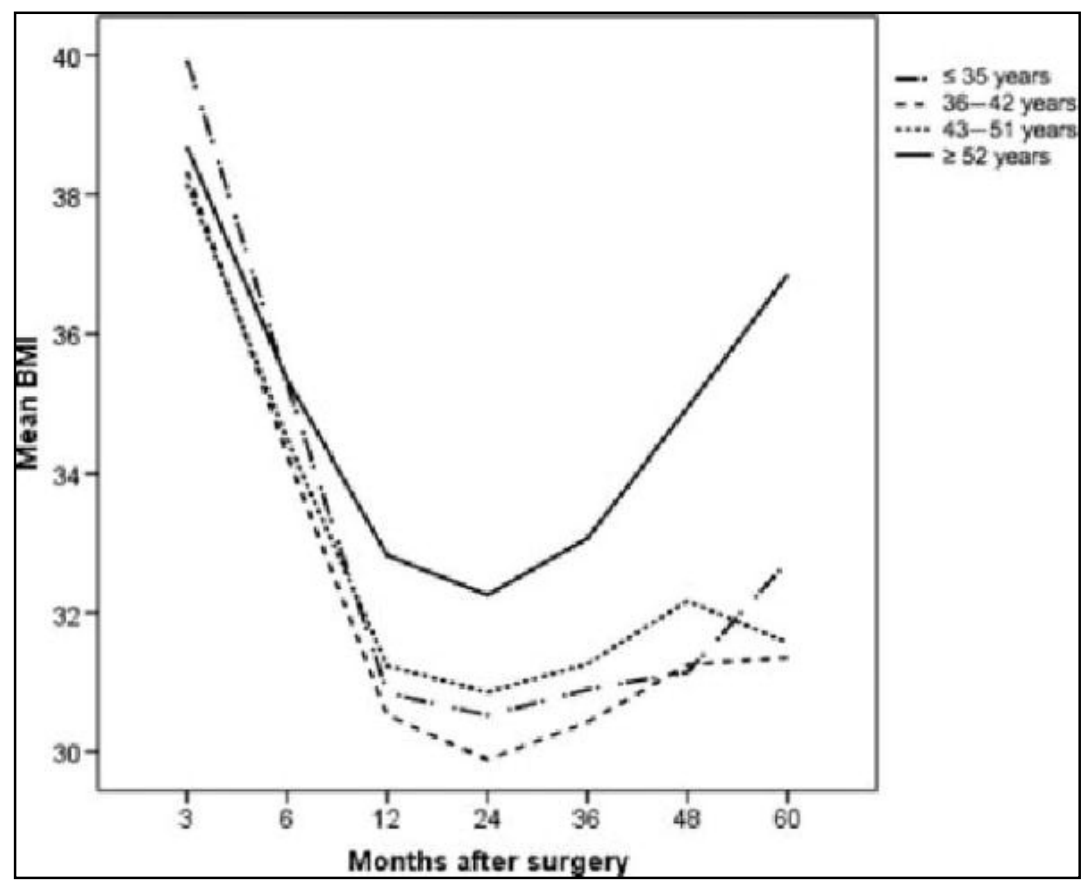

FIGURE 3 . Observed marginal means of BMI by age subgroups during the follow-up period. 